\title{
A NECESSIDADE DE UM TRABALHO PREVENTIVO EM MATERNIDADE: INSTRUÇOES SOBRE O COMPORTAMENTO DO RECEM-NASCIDO*
}

\section{THE NEED FOR PREVENTIVE ACTION IN MATERNITY WARDS: INSTRUCTIONS IN NEONATE'S BEHAVIOR}

\author{
Simone Gasparetto ${ }^{1}$
}

Vera Silva Raad Bussab ${ }^{2}$

GASPARETTO, S.; BUSSAB, V. S. R. A Necessidade de um Trabalho Preventivo em Maternidade:, struções sobre o Comportamento do Recém-Nascido. Rev. Bras. Cresc. Des. Hum., São Paulo, IV(2), 1994.

Resumo: Na medida em que se tem observado a precocidade dos comportamentos e reações do recém-nascido é de fundamental import ncia que o adulto que o manipula esteja consciente das possibilidades de respostas que um bebê pode dar quando recebe estímulos apropriados. O objetivo do presente trabalho é descrever as reações de bebês recém-nascidos a procedimentos empregados em maternidade, com sentido de avaliar a adequação destas práticas e, avaliar o quanto estas reações são consideradas pela equipe materno-infantil.

Palavras chave: Comportamento neonatal, interação mãe-bebê, responsividade do adulto, cuidados em materlade.

Sumary: Since the precocity of the neonate's behaviors and reactions has been observed and analised, it is mental that the adult who manipulates the neonate is conscious of the possibilities of answers the infant erform when receiving appropriate stimuli. The aim of this work is to describe and evaluate the neonate's ions to the proceedings used in maternity wards. The authors will also evaluate the suitabiliiy of these ices, as well as how the neonate's reactions are considered by the maternity staff.

Key-words: Neonatal behavior, mother-infant interaction, adult responsiveness, maternity care.

\footnotetext{
* Parte da tese de mestrado defendida em março de 1994, no instituto de Psicologia/USP, sob o título "Padrões e Estados Comportámentais de Recém-nascidos durante o Banho em Maternidade: Possibilidades de Regulação e Trocas Sociais”. Financiado pelo CNPq.

1 Psicóloga, mestre em Psicologia ExperimentaWSP e Doutoranda em Psicologia Experimental/USP.

2 Profa. Dra. do Departamento de Psicologia Experimental - Instituto de Psicologia da Universidade de São Paulo. Pesquisadora do CNPq.

End.: Av. Prof. Mello Moraes 1721, São Paulo - SP, CEP 05508-900 CX 66.261 Fone: (011) 818.4001
} 


\section{INTRODUÇÃO}

Há um interesse cada vez maior em se compreender o recém-nascido e avaliar a adequação dos procedimentos de cuidado na maternidade, na medida em que se tem demostrado níveis de complexidade nas reações comportamentais de neonatos e dada a crescente constata,cão da importância das experiências iniciais no desenvolvimento.

Inúmeros estudos sobre o comportamento do bebe recém-nascido (RN) vêm sendo feitos, com o objetivo de identificar padrões que reflitam a sua maturação ou as características adaptativas de suas respostas perceptuais, cognitivas ou sensório-motoras. Estes padrões incluem irritabilidade ou emoção, níveis de atividade, intensidade de reações, responsividade para os estímulos físicos e para o meto social.

Brazelton, em 1973, sistematizou a Escala Neonatal de Avaliação Comportamental, e definiu seis estados comportamentais, a saber: (1) sono profundo; (2) sono ativo; (3) sonolência; (4 alerta tranquilo; (5) despertar ativo; e (6) choro intenso; considerando-os como um dos principais tópicos do exame comportamental e como uma matriz para a compreensão das reações dos bebes. A maneira pela qual o bebê responde aos estimulas apropriados ou inapropriados demonstra a complexidade de um sistema nervoso central intacto e adaptável (BRAZELTON, 1984).

A interação do bebe recém-nascido com as pessoas e/ou objetos vai depender da permanência ou variação dos seus estados de sono e alerta.

O bebê mostra uma tendência para mudar para um estado apropriado em cada situação específica que se apresente. Uma estimulação mais intensa o acordará e frequentemente o colocará em alerta. Se for incomodado pela estimulação, ele reclamará e poderá finalmente chorar. Contudo, ele é frequentemente capaz de aquietar-se e de voltar para um estado de alerta ou de sono. Os padrões particulares das mudanças de estados dependem das demandas da situação, dos recursos dos bebes e de suas características individuais (CSILLAG \& GASPARETIO \& BERGAMASCO, 1992).

Há um interesse especial na análise da atuação do adulto junto ao RN, pois, esta influencia a possibilidade de o bebe manter-se num estado motivacional apropriado, assim como pode influenciar seu desenvolvimento subsequente.

A voz humana carinhosa é um estímulo eficiente para produzir interrupção de choro nas primeiras semanas de vida (PACKER \& ROSEMBLAT, 1980); é sugestivo que seja também um dos estímulos mais poderosos para deflagrar o sorriso de bebes neste mesmo período (OTTA, 1994).
Em situações naturais, as mães tendem a levar err conta os sinais dos bebês e a estimulá-los de modo a adorrnecê-los, em caso de indicadores de cansaço/irritação ou a facilitar o estado de alerta tranquilo, através de contatos físicos carinhosos, fala e troca de olharei (PAPOUSEK \& PAPOUSEK, 1984). Tem-se acumulada evidencias de que mães e filhos ajustam-se fisiológico hormonal e emocionalmente, respondendo um ao outro em níveis censoriais e sociais, que servem para manter o par unido (KLAUS \& KLAUS, 1989).

Desde as constelações pioneiras de BOWLBY (1969), sobre o desenvolvimento do apego, tem se consolidado a verificação de que o vínculo mãe-bebê emerge da intera,cão ajustada ao longo dos primeiros meses.

Além disso, a quantidade e a qualidade do contatc mãe-bebê nos primeiros dias depois do parto também parecem ser de especial importância. ANISFELD \& LIPPER (1983) observaram que mulheres que tiveran cantata ininterrupto com seus bebes durante as primeiras horas pós-parto mostraram comportamento mais afetivc nos dois dias subsequentes.

Diversas pesquisas realizadas em diferentes cultu ras demostraram efeitos duradouros da experiência inicial; ao apresentar revisão sobre o assunto, EIBL EIBESFELDT ( 1989), arrolou evidências para existência de uma fase sensível imediatamente depois dá parto, durante a qual um cantata intensificado da mãe com 0 bebê aumenta a prontidão de aceitação desta mae o ajustamento da diade e a prontidão interacional do bebê A amamentação ocorre mais cedo nos grupos de contatc intenso, e ao final do primeiro mês este grupo difere significativamente dos de controle quanto à quantidade de amamentação e de atração emocional; este últimc traço ainda é evidente dois anos depois. Eibl-Eibesfeld afirma ainda que, embora não se deva superestimar este efeito, pois as diferenças podem se desvanecer com c tempo, não se deve também subestimá-lo, pois esta experiência pode ser um facilitador importante dá desenvolvimento do apego.

Uma revisão sobre o assunto realizada por KLAUS \& KENNEL (1992), apontou dezessete estudos que apoiam a hipótese de um período sensível, facilitador da vinculação mãe-bebê, nas primeiras horas e dias depois do parto. Embora, no conjunto, esta revisão tenha mostrado a complexidade da determinação deste efeito, ficou claro que um dos falares determinantes é a experiência inicial. Dada a importância dos papéis parentais no desenvolvimento, medidas de prevenção e de facilitação durante este período sensível, podem ser de valor inestimável. 
Dados deste tipo levantam a questão de como os procedimentos empregados nas maternidades interferem na interação mãe-bebê. Convém ainda considerar que há também interesse em se avaliar a própria interação dos demais adultos com o RN na maternidade, lembrando-se a potencial sensibilidade do período para o bebê. Apenas a título de exemplo, eventos traumáticos deveriam ser evitados. Um caso extremo pode ser ilustrado pelo efeito de anoxia no parto no desenvolvimento posterior: bebés com esta história são mais sensíveis aos efeitos de separação da mãe nos meses que se seguem (BOWLBY, 1982).

\section{CAPACITAR PROFISSIONAIS PARA UMA NOVA VISÃO DO BEBE}

Através das pesquisas realizadas, concluímos que o cantata inicial mãe-bebê é de fundamental importancia para o desenvolvimento posterior da criança, como também para uma boa formação do vínculo. Desta forma, resolvemos estudar uma das situações de primeiros cuidados, em maternidade, após o nascimento do bebê.

Realizamos nosso trabalho na Maternidade de um Hospital Universitário. Nesta unidade, depois do parto, o RN é levado para uma sala de observação I e colocado em berço aquecido. Logo após, iniciam-se os procedimentos realizados pelas atendentes, enfermeiras e médicos do hospital, conforme uma rotina determinada. Depois de seis horas, os RN's passam para a sala de observação II, onde são colocados em berços normais, sem aquecimento. Ficam nesta sala sob os cuidados da enfermagem até a mãe ter condições de receber o bebê e ministrar-lhe os cuidados mínimos, para permanecer num esquema de alojamento conjunto.

Após uma investigação geral das rotinas desta maternidade, resolvemos selecionar uma situação típica para investigar, a situação de banho do RN. O banho caracteriza-se por um nível alto de manipulação do bebê. Estas manipulações podem produzir diversas reações no RN. Trata-se de uma situação que propicia uma série de trocas e ajustes interacionais entre o adulto e a criança e, portanto, potencialmente reveladora das características da reação do RN aos tipos de manipulações e da adequação do procedimento.

Na maternidade pesquisada, todas as mães, assim como a equipe de enfermagem, são preparadas com aulas de como dar o banho nos bebes. Pode-se constatar que esta preparação visa ao estabelecimento de uma série de etapas do banho e contém explicações minuciosas sobre os cuidados com a higiene e segurança do bebê. Exemplo: ini- cia-se a limpeza dos olhos com bolas de algodão e com movimentos sem retorno, do angulo interno para fora, usando uma bola de algodão para cada olho... Entretanto, nenhuma informação é fornecida a respeito das reações comportamentais do bebê ou da possível importancia de ajustes do procedimento a estas reações e da disponibilidade da tranquilização do bebê.

Com a permissão das mães e do hospital, foram realizadas gravações em vídeo dos comportamentos dos bebes antes, durante e logo após o banho, com a duração de vinte minutos. Dentre as diversas análises feitas das reações e dos estados comportamentais do RN definidos por Brazelton e dos comportamentos dos adultos, serão apresentadas as correspondentes à predominância dos estados mais tranquilos (alerta tranquilo - 4) ou mais agitados (despertar ativo 5) em função do tipo de banho. As frequências destes estados foram analisadas através de ANOVA- análise de variancia.

Durante o primeiro banho do bebê, que é dado pela atendente (nas primeiras duas horas de vida), observamos que os procedimentos do banho levaram a uma agitação todos os 32 bebes observados. Isto nos mostra que não há uma preocupação com o bebê, ou, até mesmo, existe um desconhecimento, por parte das atendentes, das reações e dos comportamentos do RN.

O banho seguinte, dado pela mãe (quando o bebê já está com vinte quatro horas de vida), é acompanhado por uma atendente que participa da situação de banho como instrutora, corrigindo quando a mãe faz algum procedimento incorreto, o que produz muitas interferências na relação da díade mãebebê, como foi possível verificar em nosso estudo.

Observamos que a presença da atendente durante o primeiro banho dado pela mãe fazia com que esta se tornasse mais preocupada com a sequência certa do banho do que com o próprio bebê. Além disso, a mãe tornava-se irritada, muitas vezes verbalizando sua irritação e mostravase cansada ao terminar o banho; e o bebê ficava a maior parte do banho agitado ou chorando.

A partir desse evento resolvemos observar 0 segundo banho da mãe em seu bebê (nas setenta e duas horas de vida do bebê) quando não havia mais a ajuda da Tendente: utilizamos, nesta análise, vinte dos trinta e dois bebés que já haviam sido filmados no primeiro banho.

Constatamos que apesar de existir, ainda, uma grande preocupação com a sequência de banho, as mães passaram a reagir mais às mudanças comportamentais de seus filhos. Assim, muitas vezes, levavam estes bebes de estados de agitação para estados mais calmos, facilitando, desta maneira, a interação entre eles. 
Nas situações analisadas, os adultos estavam mais voltados para cumprir uma rotina de higiene, com etapas bem definidas, do que para reagir aos sinais de perturbações do bebê: isto pareceu claro no caso da atendente e de certa forma era exigido da mãe, na medida em que esta foi treinada para as etapas do banho. Desta forma, foram perdidas oportunidades de trocas interacionais ajustadas. Mesmo assim, no banho em que a atendente estava ausente, as mães passaram a reagir mais aos sinais do bebê.

Gostaríamos de ressaltar, aqui, que seria útil orientar as mães, assim como a equipe de saúde materno-infantil, no sentido de aumentar sua sensibilidade às alterações de estados comportamentais dos bebes. O "estado" torna-se uma matriz para compreensão de suas reações. Ele qualifica o estímulo como apropriado ou inapropriado para a organização da criança. Para quase todos os níveis de maturação, o comportamento produzido por estímulos apropriados em "estados” apropriados demonstrará as características do sistema nervoso do RN (BRAZELTON, 1984).

Num estudo realizado por CSILLAG \& GASPARETTO \& BERGAMASCO (1992), em um outro hospital da cidade de São Paulo, o primeiro banho dado pela atendente era de maior duração e o procedimento mais voltado para tranquilização do bebê. Os bebes permaneceram mais em alerta tranquilo, já nas primeiras horas de vida, do que os bebes do presente estudo, o que reforça a suposição de que a agitação observada na situação era mais decorrente do tipo de procedimento do que de características da faixa etária.

\section{CONCLUSÃO}

Concluindo, poderíamos reforçar, mais uma vez, a importancia do esclarecimento e do aprendizado sobre os comportamentos e reações do bebê durante a estadia da mãe no hospital, pois temos neste período uma boa oportunidade de esclarecer dúvidas quanto ao desenvolvimento da criança. Como constatamos, no hospital em que realizamos nosso trabalho, existe uma preocupação com os primeiros cuidados do recém-nascido, no caso o banho, e são realizadas aulas de como cuidar da higiene da criança. Sugerimos então que, além destas aulas de higiene fossem realizadas aulas sobre os comportamentos e reações do bebê, para as mães e toda a equipe de saúde materno-infantil.

Assim, a equipe de saúde materno-infantil teria uma participação importante, não colocando impedimentos a um relacionamento adequado da mãe com seu filho, ou ainda, promovendo-o. Desta forma, a equipe multidisciplinar faria um trabalho preventivo, no sentido de propiciar um desenvolvimento sadio para a criança, uma vez que os primeiros contatos são muito importantes para o ajustamento inicial da diade mãe-bebê e facilitadores do processo de formação de apego. Outro ganho potencial seria a redução de eventos perturbadores na manipulação do bebê por parte da equipe.

No começo deste século, o advento da era moderna da medicina científica gerou o atual sistema hospitalar, determinado pelos conhecimentos crescentes da microbiologia, imunologia, nutrição e metabolismo, com decorrente diminuição na taxa de mortalidade infantil. Contudo, a aplicação dos novos conhecimentos produziu um isolamento progressivo dos bebes, de suas mães e das famílias (RICHMOND, 1992).

Este afastamento, por sua vez, gerou novos problemas decorrentes da falta de contato mãe-bebê durante um período sensível. Esta questão vem sendo investigada nas últimas décadas, e apesar do enorme progresso decorrente destas pesquisas esclarecendo a importância do período neonatal para o desenvolvimento, parece existir, em diversos setores, uma latência para a assimilação destes resultados dentro da maternidade.

A aplicação dos conhecimentos sobre a importância das experiências iniciais neonatais no desenvolvimento do bebê tem sido feita de maneira fragmentada e parcial. Mudanças de procedimentos, tais como 0 estabelecimento de alojamento conjunto, embora muito favoráveis, nem sempre garantem mudanças efetivas nas experiências produzidas. Pesquisas de campo sistemáticas, associadas a cursos de formação e de treinamento, parecem necessários, mesmo porque é preciso que ocorra uma modificação básica de atitude quanto aos fatores relevantes na situação de atendimento em maternidade.EIBLEIBESFELDT, I. Human ethology. New York, Aldine de Gruyter, 1989. 


\section{BIBLIOGRAFIA}

ANISFELD, E.; LIPPER, E. Early contact, social support, and mother-child bonding. Pediatrics, 72:79-83, 1983.

BOWLBY, J. Attachment anti loss: attachment. New York, Basic Book, 1969.

BOWLBY, J. Formação e rompimento de vínculos afetivos. São Paulo, Ed. Martins Fontes, 1982.

BRAZELTON, T. B. Competência comportamental do recém-nasci. do. In: GORDON, B. A. Neonatologia fisiopatologia e tratamento do recém-nascido. Rio de Janeiro, Ed. Médica e Científica Ltda.,1984.

BRAZELTON, T. B. Neonatal behavioral assessment scale. London, Willian Heinemann Medical Books, 1973.

CSILLAG, S.; GASPARETIO, S.; BERGAMASCO, N. H. O estada 4 - uma possibilidade para processos perceptivos e para interação. In: XXII Reunião Anual de Psicologia de Ribeirão Preto. Ribeirão Preto, 1992.
KLAUS, M. H.; KLAUS, P. O surpreendente recém-nascido. Porto Alegre, Ed. Artes Médicas, 1989.

KLAUS, M. H.; KENNEL, J. H. Pais/bebê - a formação do apego. Porto Alegre, Ed. Artes Médicas, 1992.

MAZET, P.; STOLURE, S. Manual de psicopatologia do recém-nascido. Porto Alegre, Ed. Artes Médicas, 1990.

O11A, E. O sorriso e seus significados. São Paulo, Ed. Vozes, 1994.

PACKER, M.; ROSEMBLAT, D. Issues in the study of social behavior in the first week of life. In: DUNN, J. The first year of life. New York, Willey \& Sons, 1980.

PAPOUSEK, H.; PAPOUSEK, M. Learning and cognition in the every day life of human infants. Adv. Stud. Behav., 14: 1984.

RICHMOND, J. B. Introdução. In: KLAUS, M. H.; KENNEL, J. H Pais/bebês a formação do apego. Porto Alegre, Ed. Artes Médi cas 1992.

recebido em: 05/04/9 aprovado em: 18/05/9 